\title{
Salmonella Isolated in CSF of Newborn: Case Report
}

\author{
Swati Gupta*, Anupama Mittal, Shallini Kakar, Poonam Gupta and Shalini Kakar \\ Department of Microbiology, Deen Dayal Upadhyay Hospital, \\ Hari Nagar, New Delhi-64, India \\ *Corresponding author
}

A B S T R A C T

\section{Keywords \\ Salmonella, CSF, \\ Newborn \\ Article Info \\ Accepted: \\ 26 May 2018 \\ Available Online: \\ 10 August 2018}

\section{Introduction}

Salmonella is a gram-negative motile bacilli causes typhoid fever, focal septic infections, septicemia, and diarrhea. It colonizes a wide range of mammalian hosts. In humans Salmonella causes four forms of infections including enteric (68\%), sepsis (8\%), nonenteric focal infections (7\%, including meningitis i.e. $0.8 \%$ ) and a chronic carrier state (15\%) (Saphra and Winter, 1957). In developing countries a rare cause of meningitis is Salmonella which is prevalent mostly among infants and young children (Keusch, 1998). It is known to be the fourth cause of meningitis in children, after Neisseria meningitidis, Streptococcus pneumoniae, and Haemophilus influenzae type $\mathrm{b}$ (H.i b). First case of Salmonella meningitis was reported by GHON in year 1908.
Salmonellosis is a widespread food born disease encountered frequently in countries with sanitation problem. Meningitis due to Salmonella carries a higher morbidity and mortality than that caused by other bacteria (John et al., 2010). Mortality rates of $40 \%$ are reported for children due to Salmonella meningitis.

Among survivors, common complications are seizures, hydrocephalus, subdural empyemas, and permanent disabilities such as retardation, paresis, athetosis, and visual disturbances.

\section{Case report}

A 23 days old girl was brought in pediatrics emergency department of our hospital with complaints of cough, cyanosis on \& off since 7 days and difficulty in breathing since 1 day. 
Past history revealed that she was delivered by Em LSCS in view of hypertensive mother. Her birth weight was $2.5 \mathrm{~kg}$ and she cried immediately after delivery with no antenatal, intranatal and postnatal complications

On initial examination HR was 148/min, RR was $64 / \mathrm{min}$, crepts \& wheeze were present on chest examination.

On CNS examination reflexes, tone was present. Suckling was also present and RBS was $88 \mathrm{mg} / \mathrm{dl}$.

After 4 days patient developed seizures, her neck reflexes were inconsistent, tone was increased \& RBS was $75 \mathrm{mg} / \mathrm{dl}$

On CSF examination protein was $98 \mathrm{mg} \%$, sugar $51 \mathrm{mg} \%$, 20 cells $/ \mathrm{mm} 3$ were seen in which $80 \%$ were mononuclear cell and 20\% were polymorphs. Salmonella species was isolated in culture report which was

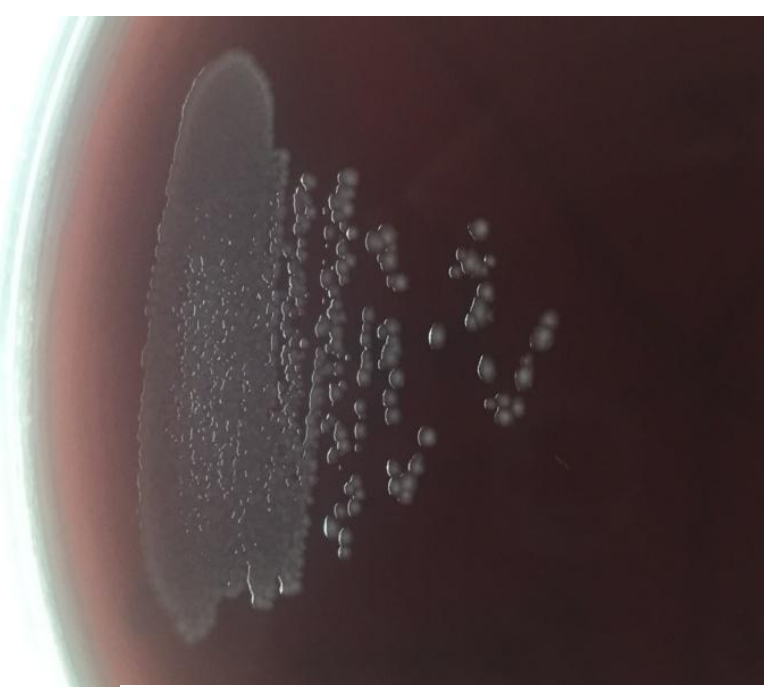

Salmonella on Blood agar

Human infection with Salmonella is most commonly caused by ingestion of food, water or milk contaminated by human or animal excreta. Younger children are more prone to get infections as they have poor macrophage function, poor antibody level, poor opsonin agglutinating with ' $\mathrm{O}$ ' antisera. Blood culture was negative. Gram stain was showing 0-1 pus cell /OIF. Salmonella isolate was sensitive to Ofloxacin, Piperacillin tazobactum combination, Netilimycin, Ciprofloxacin, Cefazolin, Levofloxacin, Amoxiclav, Amikacin, Gentamycin, Ampicillin, Cefotaxime. On giving Cefotaxime and Piperacillin Tazobactum combination the patient recovered on $5^{\text {th }}$ day.

\section{Results and Discussion}

Though meningitis due to Salmonella is very rare but it is very important problem in developing countries due to the high morbidity and mortality rates associated with this infection. Salmonella infection occurs on account of poor socioeconomic status and poor hygiene practices. Human infection caused by Salmonella is mainly manifested as typhoid fever. But meningitis caused by Salmonella is often under notified.

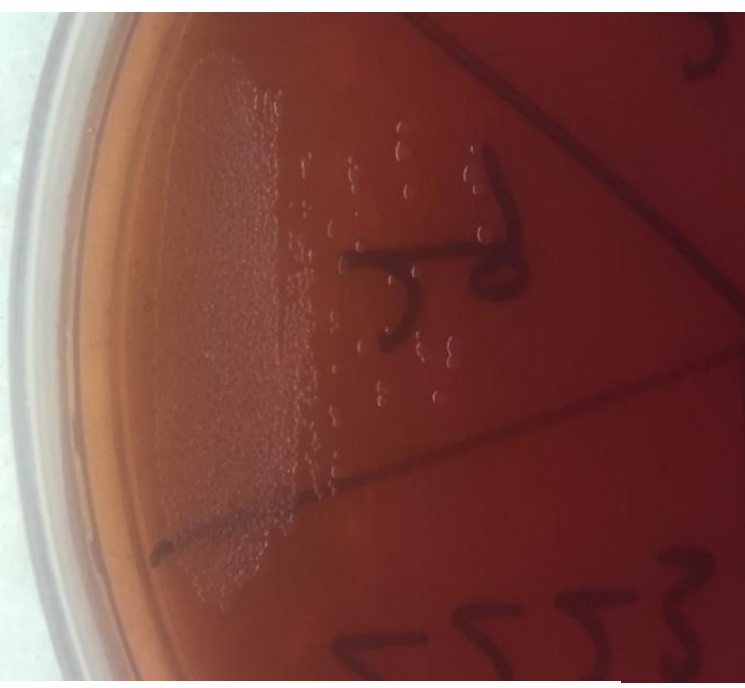

Salmonella on Macconkey agar

activity and decreased neutrophil intracellular killing function (Ogubuike and Annapurni, 1988).

In developing countries Salmonella should also be kept in mind as a possible pathogen 
while culturing CSF in cases of meningitis especially in the under 1year age group. Rate of mortality and morbidity in infants can be reduced by considering the rare causes also.

\section{References}

John ST, Al Ajmi M, Al Othman N. Neonatal meningitis caused by Salmonella enteriditis with multiple brain abscess: A case report. Kuwait Med J. 2010; 42: 74-6.

Keusch GT. Salmonellosis. In: Fauci AS, Braunwald E, Isselbacher KJ, Wilson
JD, Martin JB, Kasper DL, et al., editors. Harrison's Principles of Internal Medicine. 14th ed. New York: McGraw-Hill; 1998. pp. 950-6.

Ogubuike E, and Annapurni JT, Washington DC. Salmonella meningitis in infancy. Journal of the medical association 1988 : 80(7): 824, 825, 829.

Saphra J, and Winter JW. Clinical manifestations of salmonellosis in man: an evaluation of 7779 human infections identified at the New York Salmonella Center. N Engl J Med 1957; 256: 112834 [PubMed).

\section{How to cite this article:}

Swati Gupta, Anupama Mittal, Shallini Kakar, Poonam Gupta and Shalini Kakar. 2018. Salmonella Isolated in CSF of Newborn: Case Report. Int.J.Curr.Microbiol.App.Sci. 7(08): 4702-4704. doi: https://doi.org/10.20546/ijcmas.2018.708.494 